\title{
Transformation and Inheritance of Suzhou Pingtan in the Context of Intangible Cultural Heritage*
}

\author{
Mengxing $\mathrm{Fu}$ \\ Fuzhou University \\ Xiamen, China 361024
}

\author{
Zhixiong Huang \\ Fuzhou University \\ Xiamen, China 361024
}

\begin{abstract}
Culture is the foundation of a nation depends on for survival and development, and also the long-term historical experience accumulation of the nation. The five thousand years of history of China has left us brilliant cultural heritage. However, with the deepening of globalization and the modernization of science and technology, more and more intangible cultural heritage of China is on the verge of extinction. Many technologies and arts depending on oral transmission have less and less functions in daily life, thus starting to decline and fade away gradually. Therefore, it is necessary to find out the countermeasures of intangible cultural heritage protection and inheritance problems. This paper, starting from the transformation of Suzhou Pingtan, analyzes the current situation and problems Suzhou Pingtan faces, explore and study the "active inheritance" of Pingtan art and skills, aiming to provide forward guidance for the protection of intangible cultural heritage.
\end{abstract}

Keywords-intangible cultural heritage; Suzhou Pingtan; transformation and inheritance

\section{INTRODUCTION}

Originated from scenic Suzhou, Suzhou Pingtan widely spread in the Yangtze River Delta regions with the history, and it is the general term of Suzhou Pinghua and Suzhou Tanci. Suzhou Pingtan based on artistic expression methods mainly include "telling, releasing watercooler moment, playing stringed instruments and singing" is also known as "the living fossil of Chinese folk art forms" and was included into the first list of national intangible heritage. As early as more than four hundred years ago, the Ming dynasty, storytelling was found in Suzhou area. As recorded in Wuxian Records, "Tanci and Pinghua prevail in Ming and Qing dynasties, but the two are different. The wording 'storytelling' as a general term of the both is originated from Wuzhong". [1] In the end of the 20th century, Suzhou Pingtan started to decline and fade away, whose survival and development is facing an unprecedented crisis, and it is urgent to rescue and support it.

\section{ANALYSIS OF THE CURRENT SitUATION OF SUZHOU PINGTAN}

Through hundreds of years of social change and cultural inheritance, Suzhou Pingtan with its unique artistic characteristics has developed a school of its own and is called

*Fund project: 2016 Social Science Planning Project of Fujian Province (FJ2016B215). as "a miracle of the south of the Yangtze River". Hu Qiaomu has said, "Suzhou Pingtan, a unique of China" which is a high praise for Suzhou Pingtan; the famous master of Chinese culture of Taiwan- Mr. Yu Dagang has called Suzhou Pingtan "the most beautiful voice of China". [2] After several generations of development and inheritance, now Suzhou Pingtan has its audience all over the world.

Today, with the rapid economy development, the social structure of the ancient city Suzhou has also changed dramatically in the 21 st century. The quickening pace of life sweeps away people's mood to enjoy life, and the ancient city loses its former charm. In addition, the rise of emerging entertainment ways, the pouring in of floating population and the impact of fast food culture have greatly endangered the ecological environment of Suzhou Pingtan and caused the loss of audience. In the meantime, the lack of successor of Pingtan artists, the loss of audience, the shrinking of the cultural space of story-telling, the outmoded booklist and the decline of book quality, etc. directly cause Suzhou Pingtan to decline and fade away.

\section{TRANSFORMATION OF SUZHOU PINGTAN IN THE NEW ERA}

\section{A. Create All-media Transmission Channel}

In the new media age, the traditional transmission channels of Chines opera, such as via teahouse, broadcast and art channel, etc. cannot meet people's spiritual needs any more. Modern people are more willing to obtain information through more diversified emerging channels such as the internet, television, film and theater. Suzhou Pingtan, as a unique through more than 400 years of inheritance, also should keep up the pace of the times to expand its influence and its transmission channels via the internet, as well as take full advantage of the powerful functions of information dissemination, social education, entertainment and interactive services of the new information age. For example, we can hold Pingtan contests, art exchange sessions and other forms of activities, in addition to introducing all kinds of online and offline media vehicles such as Weibo, WeChat, broadcasting station, etc. to promote outstanding Pingtan works and realize multi-channel dissemination and presentation of them.

The official website of Shanghai Pingtan Troupe deserves to be called the leader in propagandizing Pingtan by using the new media technology and the whole website page is concise 
but with complete information, providing an efficient platform for the transmission of Pingtan. In the homepage of the website, six columns including Profile of the Pingtan Troupe, Performance Information, Dynamic News, Intangible Cultural Heritage, Hobby, etc. are established based on fixed layout, which are easy for people to search for information they need. Since its establishment in 2004, reflecting the promising development space of Pingtan. This website also has the friendly links to China Pingtan Website, Suzhou Pingtan School, Himalaya FM, etc. and, by establishing Shanghai Pingtan Troupe WeChat official account and online radio official account, builds a faster three-dimensional transmission channel. In addition, Suzhou Pingtan Troupe also makes full use of We-Media including Weibo, WeChat, etc. and adopt network communication, interpersonal communication and mass communication to break the time and space restrictions on Pingtan development.

\section{B. Animation and Suzhou Pingtan}

With the double impact of the increasing diversity of modern social culture and foreign culture, traditional culture losses a large number of receivers, especially there are major losses of receivers of, especially teenager audience who are not willing to spend time in Pingtan art with slow rhythm. Suzhou Pingtan has been included into the "List of National Intangible Cultural Heritage" and has been protected by the country by a series of measures such as collecting, integrating and duplicating the endangered plays and works among the folk. Although these measures reserve many historical voices, they cannot promote the development of Pingtan art in a positive way. According to Xing Yanzhi, a Pingtan artist, innovation is the fundamental reason for culture to maintain vitality and get sustainable development vigor, and the nourishment of other arts can provide fresh nutrients for the development of Suzhou Pingtan. As the newcomer of arts, animation can propagate culture to audience in an interesting way when entertaining the public, which undoubtedly provides new strength for protecting and inheriting Suzhou Pingtan.

The introductory song to Tanci Wang Dakui Picking Up Eggs of A famous Pingtan artist Zhang Jianting was presented in the form of animation, and this artistic expression form was the first time in China so it is honored as "fashion cultural product of Chinese folk custom tradition (including Chinese folk art forms)"[3]. This new form of communication not only arouses the feelings of the regular audience of Pingtan but also makes it popular among teenagers. Afterwards, the second animation Pingtan The New Mulan Ballad with the original sound of the famous Suzhou Pingtan actress came into the view of the public. Although these animation Pingtan works are not perfect in terms of presentation, they use the new media form of animation to try to cater the aesthetic taste of teenagers to integrate the great and profound traditional Chinese culture and modern presentation methods so as to widen the depth of animation and the breadth of culture.

Animation is a synthetic art that can bring joy to people and also implies educational significance. With the rapid development of internet, the era of new media follows, leading to arbitrary transmission of all kinds of information on the internet. Animation, as an emerging media culture, is popular with teenagers and plays an important role in promoting the spreading of traditional culture. The decline of Pingtan art is mainly because of lack of the audience, more specifically, lack of young audience, but if we expand adolescent audiences by utilizing new forms of transmission channels, and undoubtedly, this can make the traditional culture continue so as to solve the problem of endangered Suzhou Pingtan.

Integrating cultural elements of Pingtan into animation will open up a new way for the development of traditional culture. It guides Suzhou Pingtan to go forward to a new life from the crisis, and is of great significance to its creation and culture development.

\section{Television and Suzhou Pingtan}

So far, films and television is still the main channel for spreading Pingtan culture. Some literary and art workers adapted Pingtan themes into film and TV dramas, not only to enrich the connotation of film and television, but also to create new vitality for the spread of Pingtan art. With the enchantment of Pingtan culture, the historical connotation of these films and television programs attracts audiences to explore and comprehend with all their hearts, thereby adding endless charm to the films and television programs. Taking example for some movies - If You Are The One, Everlasting Regret, Lust, Caution, Lust or Love, The Flowers Of War, In the Mood for Love, and drama series — Jiangnan Pearl, The Lost Tomb, while these works ensure the traditional inheritance mode of Pingtan and maintain the refined and elegant quality of Pingtan, they also extend the contact space between Pingtan and modern life, and let Pingtan enter the perspective of modern people. In the Flowers of War, QingHuai Scenery sings out the Jiangnan women's gentle and tenacious character, and deepens the characters' connotation. The scene of In the Mood for Love is set in Shanghai which is more elegant and charming with the background of the Suzhou soft dialect of Suzhou Pingtan, and more audiences have an intuitive experience of Pingtan art. In the story line of Lust, Caution, Lust or Love, the off-screen sound of Wang Jiazhi's first appearance is the selection Jiange Wenling of Palace of Eternal Life singed by Jiang Yuequan. This selection tells the story that Emperor Xuanzong of Tang Dynasty had to give Lady Yang to death after fleeing to Mawei Po during the An Lushan Rebellion. After that, he spent the night in Jiange County and mourned for Lady Yang. The movie reflects the tragic ending of Wang Jiazhi's death by the death of Lady Yang. In the drama series of Jiangnan Pearl, Pingtan artists' real love, hate, sorrow and joy are also implanted in the traditional Pingtan bibliography "Jade Dragonfly". In "Jade Dragonfly", secret affairs of You An, giving birth in the cloud room, running for son in the hall, recognizing mother in buddhist convent, the four climaxes run through the play, which makes that the plot of series is intertwined and promoted[4] with the plot of "Jade Dragonfly". Pingtan is increasingly popular among people and has more widespread artistic forms of expression due to the spread of modern media such as film and television. The modern media industry integrates Pingtan art into the form of expression, creating a new prospect for its own rich artistic implication. 


\section{Modern Drama and Suzhou Pingtan}

In order to commemorate the 100th anniversary of the birth of Cao Yu, Suzhou Pingtan Troupe gave the performances of the mid story Pinghua Thunderstorm adapted from Cao Yu's same name drama in Peking University, Tsinghua University, Nankai University and Chang'An Grand Theater, Mei Lanfang Theatre, which were played and sang by Sheng Xiaoyun, $\mathrm{Xu}$ Huixin, Shi Bin, Wu Jing and Chen Dan. Huang Huilin, a dramatic film and TV expert, commented: "the choreography and performance are all in place, surprisingly good! The classics are alive again by virtue of Suzhou Pingtan," [5].

\section{MEASURES FOR INHERITING SUZHOU PINGTAN}

\section{A. Caring for the Aged Audience and Cultivating the Young Audience}

Although the Pingtan art is an oral culture that was born in the old society for killing time, it has been a classic art after several generations of people's inheritance and development. It should be said that when the audience reach a certain age, have rich life experience, cultural and artistic accomplishment, they can better appreciate her charm. When people reach a certain age and enough leisure time, they will unconsciously find a deeper, more elegant and leisurely cultural enjoyment, such as Pingtan art.

In recent years, some story-telling houses subsidized by the government and some Pingtan fans have sprung up in succession. Many public welfare houses' fares are very low and the rest are sponsored by the government. The story-telling houses have become the best entertainment places for community residents. If every town and street opens a house in accordance with the government's plan, the scarcity of performance personnel will not meet the needs of the market. Therefore, Pingtan practitioners need not to sigh "only the elderly audience", but to pay more attention and concern to them. While maintaining the middle and old audience, they shall as well as train as many young audiences as possible. And young people are the power of the future industry, and the applause from them is the hope of Suzhou Pingtan's future.

\section{B. Qualified Ideas of Education for All}

The protection and inheritance of intangible cultural heritage is a great and difficult undertaking. This work and attempt should not only rely on the contemporary people's full implementation, but also depend on the support and efforts of future generations. The education and inheritance of intangible cultural heritage are not only a process that national folk culture resources that have been neglected for a long time entering the field of education, and a continuation of the memory of ancient life of the nation, but also a cognitive process of national existence spirit, survival wisdom and living culture, and a process of national culture integration with more human discovery and rational spirit. [6] Only through the cultivation of multicultural learning and inheritance skills, the public can learn to cherish the "intangible cultural heritage", shoulder the sacred duty of protection, and firmly grasp the future of heritage in the hands. There are two ways to achieve sustainable and healthy development of Pingtan by education: first, through the strict professional education and the traditional master and apprentice of oral or mental instruction, to cultivate professional talents who love Pingtan and play well. For example, in order to foster the Pingtan art school, Suzhou Pingtan School, vocational education has been increasingly involved in the inheritance of intangible cultural heritage. Second, through basic music education, to arouse the consciousness of the people to protect Suzhou Pingtan, which creates a sense of mission and identity towards intangible cultural heritage fundamentally. The government can compile Pingtan music teaching materials suitable for basic education and offer Pingtan art related courses to students, so as to lay a solid foundation for inheriting excellent regional culture, display the art charm of Pingtan and train Pingtan enthusiasts. It is necessary to guide students who never know Pingtan to know Pingtan, and then love Pingtan, so that traditional cultural resources can be turned into a realistic cultural productivity.

\section{Development of Suzhou Culture and Tourism Industry with Pingtan as the Carrier}

In the low carbon economy era, the cultural industry and tourism industry, as "green sunrise industries", have always been the priorities and development objects of the state and the government. Culture is the soul for tourism; tourism is an important way for the development of culture. As a historical and cultural ancient city, Suzhou has its unique cultural connotation which is composed of poetic gardens, simple and elegant ancient architecture complex and graceful and vivid Suzhou Pingtan. With the continuous improvement of people's material living standard, the traditional landscape tourism is lack of experience and deep sightseeing, which cannot meet the growing spiritual needs of tourists, and they begin to pay more attention to the cultural connotation of the tourist sites. As a regional culture in Suzhou, Pingtan art takes the most popular, lifestyle and folklore art form and content, which reflects people's unique life interest, contains a lot of social and historical information, and represents the aesthetic direction of people. And its unique cultural personality has an important economic significance in the development and marketing of tourism products. We can promote the Pingtan performance in the attraction teahouses of scenic spots, adopt the market-based performance form, and develop the corresponding Pingtan derivatives. Pingtan art and its derivatives form an industrial chain together to create brand and endow the traditional culture with vitality. And it will help to enhance the artistic image of Pingtan in the hearts of tourists and promote the protection and inheritance of intangible cultural heritage.

\section{CONCLUSION}

Although the Pingtan art is temporarily in the state of malaise, with the support of the government and the efforts of the people, with the awakening of regional culture, the string music that has been inherited for more than 400 years will certainly resound. The inheritance and protection of Suzhou Pingtan art requires the concerted efforts of vast number of music practitioners, learners and Suzhou Pingtan enthusiasts. In the new era, in order to innovate and maintain the vitality of Pingtan art, transformation is a necessary way. We should make full use of modern science and technology to spread 
Suzhou Pingtan to a wider space and make it popular in the masses. For us, better protection of Pingtan is the responsibility and mission that history gives us. And we should make efforts that the ancient intangible cultural heritage can better serve the modern society and traditional cultural resources can become a realistic cultural productive force.

\section{REFERENCES}

[1] Cao Yunyuan, Li Genyuan, Wu Xianzhi (Volume 12 of Jiangsu Chronicle of China's Local Chronicles) [M] . Nanjing: Jiangsu Ancient Book Publishing House, 1991. 曹允源, 李根源. 吴县志 (中国地方志集成·江苏府县志辑第 12 册) [M]. 南京: 江苏古 籍出版社, 1991.

[2] $\mathrm{Wu}$ Enpei. Introduction to Wu Culture [M]. Nanjing: Southeast University Press, 2006.233-236. 吴恩培.吴文化概论[M] . 南京: 东南 大学出版社, 2006.233-236.

[3] Wang Shubin. Ququ Liyin Dai Xianqi [N]. Wen Hui Bao, 200810-13. 王树滨. 曲曲丽音带仙气 [N] . 文汇报, 2008-10-13.

[4] Hong Xin. Pingtan's relationship with television: Comment of Jiangnan Pearl [J]. Shanghai Theater, 1988（3）：13-14.洪欣. 赞评弹与 电视结缘: 兼评电视连续剧《江南明珠》 [ J ] . 上海戏剧, 1988 (3) : 13-14.

[5] Zhu Donglin. Classic Thunderstorm: From Drama to Suzhou Pingtan [J]. LiteraryReview, 2011(2). 朱栋霖. 经典《雷雨》: 从话剧到苏州评弹 $[\mathrm{J}]$. 文学评论,2011(2).

[6] Pu Lichun, Yuan Fei. Main Body and Role of Education and Inheritance of Intangible Cultural Heritage of Ethnic Minorities [J]. Ethnic Education Study, 2012(1). 普丽春、袁飞. 少数民族非物质文化遗产教 育传承的主体及其作用 [J]. 民族教育研究, 2012(1). 